BMJ Open

Sport \&

Exercise

Medicine

\title{
Risk factors for exertional rhabdomyolysis with renal stress
}

\author{
Terje Apeland, ${ }^{1}$ Tore Danielsen, ${ }^{2,3}$ Eva M Staal, ${ }^{1}$ Anders Asberg, ${ }^{4}$ Inga S Thorsen, ${ }^{1}$ \\ Tom Ole Dalsrud, ${ }^{2,5}$ Stein $\varnothing \mathrm{rn}^{6}$
}

To cite: Apeland T,

Danielsen T, Staal EM, et al. Risk factors for exertional rhabdomyolysis with renal stress. BMJ Open Sport Exerc Med 2017;3:e000241. doi:10.1136/bmjsem-2017000241

Accepted 26 May 2017

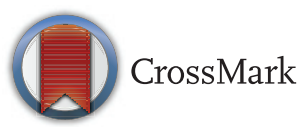

${ }^{1}$ Department of Medicine, Stavanger University Hospital, Stavanger, Norway ${ }^{2}$ FSAN, Norwegian Armed Forces, Stavanger, Norway ${ }^{3}$ Birkenes Medical Centre, Birkeland, Norway

${ }^{4}$ Department of Transplantation Medicine, Oslo University HospitalRikshospitalet, Oslo, Norway ${ }^{5}$ Stavanger Emergency Medical Centre, Stavanger, Norway

${ }^{6}$ Department of Cardiology, Stavanger University Hospital, Stavanger, Norway

Correspondence to Dr Terje Apeland; terje. apeland@lyse.net

\section{ABSTRACT}

Background Exercise-induced rhabdomyolysis denotes the exertional damage of myocytes with leakage of sarcoplasmic content into the circulation. The purpose of this study was to determine important risk factors for the development of exertional rhabdomyolysis in a temperate climate and to study the renal effects of myoglobinuria.

Methods A cluster of eight military recruits was admitted to hospital due to exertional rhabdomyolysis with myoglobinuria. The patients were treated according to current guidelines with isotonic saline and alkalinisation of the urine. The eight patients were compared with a randomly selected control group of 26 healthy fellow recruits. All subjects responded to a standardised questionnaire.

Results There were little differences in baseline characteristics between patients and controls. In the present study, exercise intensity, duration and type were all significant determinants of exertional rhabdomyolysis in univariate models. However, in a multivariate model, high exercise intensity on day -1 was the only significant predictor of rhabdomyolysis $(p=0.02)$. All patients had a stable serum creatinine and cystatin $\mathrm{C}$. There was a significant increase in serum neutrophil gelatinase-associated lipocalin (NGAL) in the patients, suggesting renal stress.

Conclusions Sustained maximal intensity exercise is a crucial risk factor for rhabdomyolysis with gross pigmenturia. Elevated serum NGAL concentrations indicate the presence of renal stress. It appears to be possible to quantify the risk of rhabdomyolysis by means of a simple questionnaire. In the future, this may be used as a tool to prevent rhabdomyolysis.

\section{INTRODUCTION}

Rhabdomyolysis denotes the injurious breakdown of skeletal muscle cells. Clinically it is characterised by local pain, weakness and swelling, with leakage of sarcoplasmic content into the circulation, such as creatine kinase (CK), myoglobin and aspartate aminotransferase. The myocytes may be injured in many different ways, for example, by mechanical trauma, hypoxia, drugs, toxins or infections. ${ }^{1}$ Circulating myoglobin from injured muscles is filtered in the kidneys and may cause acute kidney damage. Therefore, subjects with

\section{What is known about the subject?}

Exertional rhabdomyolysis is not uncommon and has been best defined among military personnel, with incidences from 2.2 to 13.4 cases per 10000 persons per year. The US armed forces reported a $17 \%$ increase in incidental rhabdomyolysis between 2014 and 2015, with the highest incidence rates observed in subjects who were male, younger than 20 years of age, nonHispanic, recruit trainees or in combat-specific occupations. Furthermore, there are a few civilian reports on clusters of rhabdomyolysis among athletes and students. The information on aetiological risk factors appears to be sparse and incomplete. Few publications have studied the risk factors for the development of this condition.

- It appears that the frequency of associated kidney failure is low in otherwise healthy young subjects; a range of $0 \%-8 \%$ has been reported. Previously, serum creatinine has been used as the main biomarker of kidney injury. Neutrophil gelatinase-associated lipocalin (NGAL) and cystatin C are more sensitive and are early biomarkers of kidney injury; however, few reports have been published in this context.

\section{What are the new findings?}

Sustained high-intensity physical activity exceeding muscular functional capacity, is a crucial risk factor for exertional rhabdomyolysis.

- The failure to recognise muscular pain as an important alarm signal appears to be of importance in this setting.

- A simple self-assessment questionnaire may be employed to monitor risk of exertional rhabdomyolysis.

- Although traditional markers of renal function often remain within normal limits in uncomplicated rhabdomyolysis, elevated serum NGAL may indicate the presence of renal stress or subclinical renal injury.

significant rhabdomyolysis are often hospitalised and treated with saline infusion and bicarbonate. $^{2}$ 
Exertional rhabdomyolysis may be the most common form of rhabdomyolysis, particularly in a hot climate. ${ }^{1}$ ${ }^{3}$ It may be caused either by direct mechanical injury of the sarcolemma or intracellular energy depletion with low ATP, leading to necrosis of muscle cells. ${ }^{4} 5$ The exact incidence is unknown, as many patients probably do not seek medical attention. Furthermore, the diagnostic criteria may vary. CK concentrations commonly rise after strenuous exercise. There is a floating difference between a normal postexercise rise in serum CK and a pathological CK rise due to rhabdomyolysis. ${ }^{6}$ Exertional rhabdomyolysis has been best defined among military personnel, with incidences from 2.2 to 13.4 cases per 10000 persons per year. ${ }^{7} 8$ The US armed forces reported a $17 \%$ increase in incidental rhabdomyolysis between 2014 and 2015, with the highest incidence rates observed in subjects who were male, younger than 20 years of age, non-Hispanic, recruit trainees or in combat-specific occupations. ${ }^{8} 9$ There are a few civilian reports on clusters of rhabdomyolysis among athletes and students. ${ }^{7}{ }^{10}{ }^{11}$ It appears that the frequency of associated kidney failure is low in otherwise healthy young subjects; $0 \%-8 \%$ has been reported. ${ }^{3671012}$

Most previous studies have focused on the diagnosis and treatment of exertional rhabdomyolysis. Few publications have studied the risk factors for the development of this condition. ${ }^{10}$ Exertional rhabdomyolysis attenuates physical performance, hampers progression of training and adds cost in terms of hospitalisations and sick leave. If risk factors are identified, it may be possible to implement preventive measures. The primary aim of the present study was to determine the crucial risk factors for the development of exertional rhabdomyolysis in a temperate climate. The secondary aim was to assess the renal effects of myoglobinuria by applying novel markers of glomerular filtration (cystatin C) and renal tubular stress (neutrophil gelatinase-associated lipocalin (NGAL)).

\section{METHODS}

\section{Subjects}

This is a case-control study based on a cluster of eight military recruits who were admitted to the hospital due to exertional rhabdomyolysis with gross pigmenturia. The incident occurred about 1 week after arrival in camp. All the new recruits had been divided into squads for their physical training. Importantly, the various squads had exercise programmes that differed somewhat in regard to duration, intensity and composition.

Day 0 was the day when the patients first got muscular symptoms with pigmenturia. Days -1 and -2 were before muscular injury, and days 1-24 in the time thereafter.

The control group consisted of 26 randomly selected healthy recruits from the same military camp. The healthy subjects provided blood samples while the patients still were in the hospital (day 3).

\section{Diagnostic criteria for rhabdomyolysis with pigmenturia}

There should be appropriate clinical findings and serum CK above $20000 \mathrm{U} / \mathrm{L}$. The urine should be positive for blood on dipstick test, but without haematuria on urine microscopy.

\section{Treatment}

The patients were treated according to current guidelines. ${ }^{13}$ On arrival, they were promptly volumeexpanded with intravenous isotonic saline, combined with drinking water, causing a mean urine output of $5.0 \mathrm{~L}$ per day during the hospital stay. The urine was alkalinised with bicarbonate tablets and the mean urine $\mathrm{pH}$ was $6.9 \pm 0.8$ during the stay. Patients were discharged when their condition had improved and myoglobinuria no longer could be detected with urine dipstick test. The mean duration of the hospital treatment was $4.9 \pm 0.8$ days.

\section{Clinical and demographic data collection}

Both patients and controls responded to a questionnaire about their current intake of drugs, tobacco, alcohol, diet and physical training level prior to entering military service. In the same way, information was obtained about exercise schedule and medical symptoms in the days before the rhabdomyolysis cluster occurrence. Data about body weight, height and conscription board examinations were extracted from the military medical record.

Prior to military service at conscription board examination, aerobic capacity and muscular strength were assessed with a maximal treadmill running test and two maximum isometric tests for arms and legs. ${ }^{14}$ The results were expressed in a semiquantitative scale from 1 to 9 , with 1 representing lowest and 9 best results.

In the period of muscular injury, the subjects reported their exercise type on the questionnaire: A: aerobic training; S: strength training; $\mathrm{M}$ : mixed training; No: no exercise. Exercise duration was reported in minutes. Exercise intensity was reported on a subjective scale from 1 to 10 , with 1 being the lowest and 10 the highest intensity.

\section{Laboratory methods}

All biochemical analyses were performed in serum.

Cystatin C was analysed with a particle-enhanced turbidimetric immunoassay using reagents from Gentian (www.gentian.no) on a Modular P800 analyser (Roche Diagnostics, Mannheim, Germany). Coefficient of variation $(\mathrm{CV})$ was $\leq 5 \%$. Laboratory reference interval is $0.51-1.05 \mathrm{mg} / \mathrm{L}$.

Myoglobin was analysed with the electrochemiluminescent immunoassay Elecsys (Roche Diagnostics) on a 
Modular E analyser (CV $\leq 7 \%)$. Laboratory reference interval is $30-70 \mu \mathrm{g} / \mathrm{L}$ for men.

NGAL was analysed by enzyme immunoassay (ELISA) Quantikine (R\&D Systems, Stillwater, Minnesota, USA). The assay had been validated, and kit independent controls were run on every test plate. The interassay $(n=5)$ and intra-assay $(n=10)$ variation coefficients were $4.8 \%$ and $2.3 \%$, respectively.

$\mathrm{C}$ reactive protein (CRP) was analysed by turbidimetric immunoassay using a Roche Modular kit on a Modular analyser, with $\mathrm{CV} \leq 7.5 \%$. Laboratory reference interval is $0-4 \mathrm{mg} / \mathrm{L}$.

CK was analysed by a photometric assay using the Architect Creatine Kinase Reagent Kit (Abbott Laboratories, Abbott Park, Illinois, USA) on an Architect c16000 analyser (Abbott Laboratories), with CV $\leq 6.5 \%$. Laboratory reference interval is $50-400 \mathrm{U} / \mathrm{L}$ for men between 18 and 49 years.

Creatinine concentrations were obtained by an enzymatic method using the Multigent Creatinine Assay (Sentinel CH, Milan, Italy) on an Abbott Architect c16000 analyser, with $\mathrm{CV} \leq 3.6 \%$. Laboratory reference interval is $60-105 \mu \mathrm{mol} / \mathrm{L}$ for men above 17 years.

Estimated glomerular filtration rate (eGFR) was estimated with the Chronic Kidney Disease Epidemiology Collaboration (CKD-EPI) creatinine equation. ${ }^{15}$

\section{Statistical analysis}

Age, body mass index (BMI), exercise duration, myoglobin, NGAL, CRP, creatinine, eGFR and cystatin $\mathrm{C}$ were normally distributed and analysed with appropriate Student's t-tests. Student's t-tests were two-tailed. The Mann-Whitney U test and the Wilcoxon signedrank test were applied for evaluating differences in preservice training level, muscular strength, aerobic capacity, exercise intensity and CK. Spearman rank correlation coefficient was used to explore the relationship between the duration of muscular pain and peak levels of CK and myoglobin. The $\chi^{2}$ test was used for testing categorical differences such as gender, tobacco habit, dietary additives, alcohol use and exercise type. Simple, multiple and logistic regression were employed for exploring the relationship between different risk factors and rhabdomyolysis or biochemical markers of tissue injury. $\mathrm{p} \leq 0.05$ was considered significant. The statistical calculations were performed using StatView V.5.0.

\section{RESULTS}

On arrival to the hospital, all the patients were haemodynamically stable and with normal body temperature. They had mean systolic blood pressure of $140 \pm 7 \mathrm{~mm} \mathrm{Hg}$ without evidence of dehydration. All patients had swelling of their thigh muscles with local pain, tenderness and weakness. They had darkcoloured urine-positive for blood on urine dipstick test, but without haematuria on urine microscopy- compatible with myoglobinuria. Serum potassium and calcium were within laboratory reference intervals. The patients were previously healthy and none reported any previous episodes of rhabdomyolysis.

All the subjects were asked if they had felt cold or hot during the exercise. The complaints about temperature were mild however, and no differences were detected between patients and controls. The mean outdoor temperature during this period was $17.3^{\circ} \mathrm{C}$ (maximum $\left.22.7^{\circ} \mathrm{C}\right)$.

\section{Demographics}

The patients and the controls were of the same age. One control subject was of Asian origin; the others were Caucasian. Two controls were female; the others were men (table 1). We found no significant differences between patients and controls in regard to age, diet, tobacco, alcohol and training level before entering military service (table 1). During the first 2 weeks of military service, the recruits were not allowed to leave the camp and their intake of alcoholic beverages was considered moderate.

\section{Biochemical markers of muscular injury}

The eight patients had a peak serum CK concentration of $126788 \pm 66649 \mathrm{U} / \mathrm{L}$ (mean $\pm \mathrm{SD})$, range 48861 202522 U/L. Their peak serum myoglobin concentration was $8811 \pm 6360 \mu \mathrm{g} / \mathrm{L} \quad($ mean $\pm \mathrm{SD})$, range 1698 $21298 \mu \mathrm{g} / \mathrm{L}$.

The patients had significantly higher concentrations of CK and myoglobin compared with the controls on day 3 (table 2, figure 1). There was a close correlation between $\mathrm{CK}$ and myoglobin concentrations (Spearman's $\mathrm{r}$ 0.93, $\mathrm{p}<0.0001)$. On day 24, the CK and myoglobin concentrations were significantly reduced from peak levels (table 2, figure 1).

On day 3, the 26 controls had a mean CK concentration of $1553 \mathrm{U} / \mathrm{L}$, which was above the laboratory reference interval, that is, $40-400 \mathrm{U} / \mathrm{L}$ (table 2). Of these, seven controls (27\%) had CK below $400 \mathrm{U} / \mathrm{L}$, and three had CK above $5000 \mathrm{U} / \mathrm{L}$. The mean myoglobin concentration in controls was $133 \mu \mathrm{g} / \mathrm{L}$, which was above the laboratory reference interval, that is, 30$80 \mu \mathrm{g} / \mathrm{L}$ (table 2). Of these, 11 controls (42\%) had myoglobin concentrations within the laboratory reference interval.

\section{Muscular pain}

The patients reported muscular pain and tenderness for a duration of 7-9 days (mean $8.4 \pm 0.7$ days), while the control subjects had significantly shorter duration of pain: $0-9$ days (mean 2.1 \pm 3.4 days, $\mathrm{p}<0.0001$ ). Seventeen controls $(65 \%)$ did not report muscular pain. Moreover, the patients reported higher pain intensity than controls. There was a significant, positive correlation between the peak concentrations of CK and myoglobin and the number of days with muscular pain 
Table 1 Demographics for patients and controls (ie, healthy fellow military recruits)

\begin{tabular}{|c|c|c|c|c|c|c|c|c|c|}
\hline & $\begin{array}{l}\text { Age } \\
\text { (years) }\end{array}$ & $\begin{array}{l}\text { Gender } \\
\text { (M/F) }\end{array}$ & $\begin{array}{l}\text { BMI } \\
\left(\mathrm{kg} / \mathrm{m}^{2}\right)\end{array}$ & $\begin{array}{l}\text { Tobacco } \\
\text { habit } \\
\text { (yes/no) }\end{array}$ & $\begin{array}{l}\text { Alcohol } \\
\text { use } \\
\text { (yes/ } \\
\text { no) }\end{array}$ & $\begin{array}{l}\text { Dietary } \\
\text { additive } \\
\text { (yes/no) }\end{array}$ & $\begin{array}{l}\text { Preservice } \\
\text { exercise } \\
\text { level* }\end{array}$ & $\begin{array}{l}\text { Conscription } \\
\text { board; } \\
\text { muscular } \\
\text { strengtht }\end{array}$ & $\begin{array}{l}\text { Conscription } \\
\text { board; aerobic } \\
\text { capacityt }\end{array}$ \\
\hline $\begin{array}{l}\text { Patients, } \\
n=8\end{array}$ & $19.8 \pm 1.1$ & $8 / 0$ & $24.2 \pm 4.0$ & $3 / 5$ & $6 / 2$ & $4 / 4$ & $2.5 \pm 0.54$ & $5.1 \pm 1.6$ & $3.4 \pm 0.9$ \\
\hline \multirow[t]{2}{*}{$\begin{array}{l}\text { Controls, } \\
n=26\end{array}$} & $19.5 \pm 1.0$ & $24 / 2$ & $24.5 \pm 3.4$ & $16 / 10$ & $22 / 4$ & $9 / 17$ & $2.1 \pm 0.71$ & $6.5 \pm 2.0$ & $3.4 \pm 1.4$ \\
\hline & n.s. & n.s. & n.s. & n.s. & n.s. & n.s. & n.s. & $p=0.05$ & n.s. \\
\hline
\end{tabular}

Age, BMI, preservice exercise level, muscular strength and aerobic capacity are given as arithmetic mean \pm SD.

*Questionnaire: three levels-1, no regular exercise; 2, regular exercise on an individual basis; 3, exercise organised by sports club with/ without competitions.

$\dagger$ Assessed with a semiquantitative method at the conscription board examination; nine levels (1-9)—higher is better. ${ }^{14}$

BMI, body mass index.

(Spearman's r 0.5, p=0.004 and Spearman's r 0.6 , $\mathrm{p}=0.001$, respectively).

Risk factors for rhabdomyolysis with myoglobinuria

Prior to military enrolment, patients and controls had similar aerobic capacity; however, the patients had less isometric muscular strength than the control subjects (table 1). The patients reported significantly higher exercise intensity during the 3 days before the injury cluster occurred-this was most evident on day -1 (Monday). Furthermore, the patients reported significantly longer exercise duration on day -1 , and more strength training on day 0 (Tuesday) (table 3). The strength training involved a significant amount of eccentric exercises. Importantly, all patients reported that they had kept on with the high-intensity exercises despite significant muscular pain.

On multivariate analysis (logistic multiple regression), a maximal level of exercise intensity on day -1 was the only independent predictor of rhabdomyolysis with myoglobinuria $(\mathrm{p}=0.02)$.

\section{Biochemical markers of kidney injury}

The patients had stable and normal serum creatinine of $85 \pm 12,77 \pm 7$ and $82 \pm 8 \mu \mathrm{mol} / \mathrm{L}(\operatorname{mean} \pm \mathrm{SD})$ on day 1 , day 3 and day 24, respectively. There was no difference in creatinine, cystatin $\mathrm{C}$ and eGFR between patients and controls (table 2). On day 24, all patients had a normal albumin/creatinine ratio in their urine (mean $0.5 \pm 0.3 \mathrm{mg} / \mathrm{mmol})$.

Table 2 Serum concentrations of muscular and renal biomarkers in patients and healthy controls on day 3 and in patients on day 24 after debut of rhabdomyolysis with discoloured urine

\begin{tabular}{|c|c|c|c|c|c|}
\hline & $\begin{array}{l}\text { p Difference: } \\
\text { patients versus } \\
\text { controls on day } 3\end{array}$ & $\begin{array}{l}\text { Control subjects on } \\
\text { day } 3, n=26\end{array}$ & $\begin{array}{l}\text { Patients on } \\
\text { day } 3, n=8\end{array}$ & $\begin{array}{l}\text { Patients on } \\
\text { day } 24, n=8\end{array}$ & $\begin{array}{l}\text { p Difference: } \\
\text { patients on } \\
\text { day } 3 \text { versus } \\
\text { day } 24\end{array}$ \\
\hline CK U/L & $p<0.0001$ & $1553 \pm 2094$ & $97595 \pm 60054$ & $1994 \pm 4297$ & $\mathrm{p}=0.01$ \\
\hline Myoglobin $\mu \mathrm{g} / \mathrm{L}$ & $p<0.0001$ & $133 \pm 103$ & $5223 \pm 2900$ & $269 \pm 606$ & $p=0.003$ \\
\hline NGAL $\mu \mathrm{g} / \mathrm{L}$ & $p=0.05$ & $198 \pm 59$ & $246 \pm 54$ & $186 \pm 40$ & $p=0.006$ \\
\hline CRP mg/L & $p=0.03$ & $4.1 \pm 3.9$ & $13.3 \pm 14.2$ & $2.8 \pm 2.3$ & $p=0.09$ \\
\hline Creatinine $\mu \mathrm{mol} / \mathrm{L}$ & $p=0.14$ & $84 \pm 11$ & $77 \pm 9$ & $82 \pm 8$ & $p=0.12$ \\
\hline eGFR mL/min & $p=0.14$ & $114 \pm 14$ & $123 \pm 10$ & $117 \pm 11$ & $p=0.10$ \\
\hline Cystatin C mg/L & $p=0.83$ & $0.82 \pm 0.11$ & $0.83 \pm 0.12$ & $0.91 \pm 0.10$ & $p=0.07$ \\
\hline
\end{tabular}

Data are given as arithmetic mean $\pm \mathrm{SD}$ (range).

$\mathrm{CK}$, creatine kinase, laboratory reference interval is $50-400 \mathrm{U} / \mathrm{L}$ (men 18-49 years); myoglobin, laboratory reference interval is $30-80 \mu \mathrm{g} / \mathrm{L}$ (men); NGAL, neutrophil gelatinase-associated lipocalin; CRP, C reactive protein, laboratory reference interval is $0-4 \mathrm{mg} / \mathrm{L}$ (both sexes); creatinine, laboratory reference interval is $60-105 \mu \mathrm{mol} / \mathrm{L}$ for men above 17 years; eGFR, estimated glomerular filtration rate, laboratory reference interval is $93-131 \mathrm{~mL} / \mathrm{min}$ (men $17-24$ years); cystatin $\mathrm{C}$, laboratory reference interval is $0.51-1.05 \mathrm{mg} / \mathrm{L}$ (both sexes). 
S-Creatine kinase
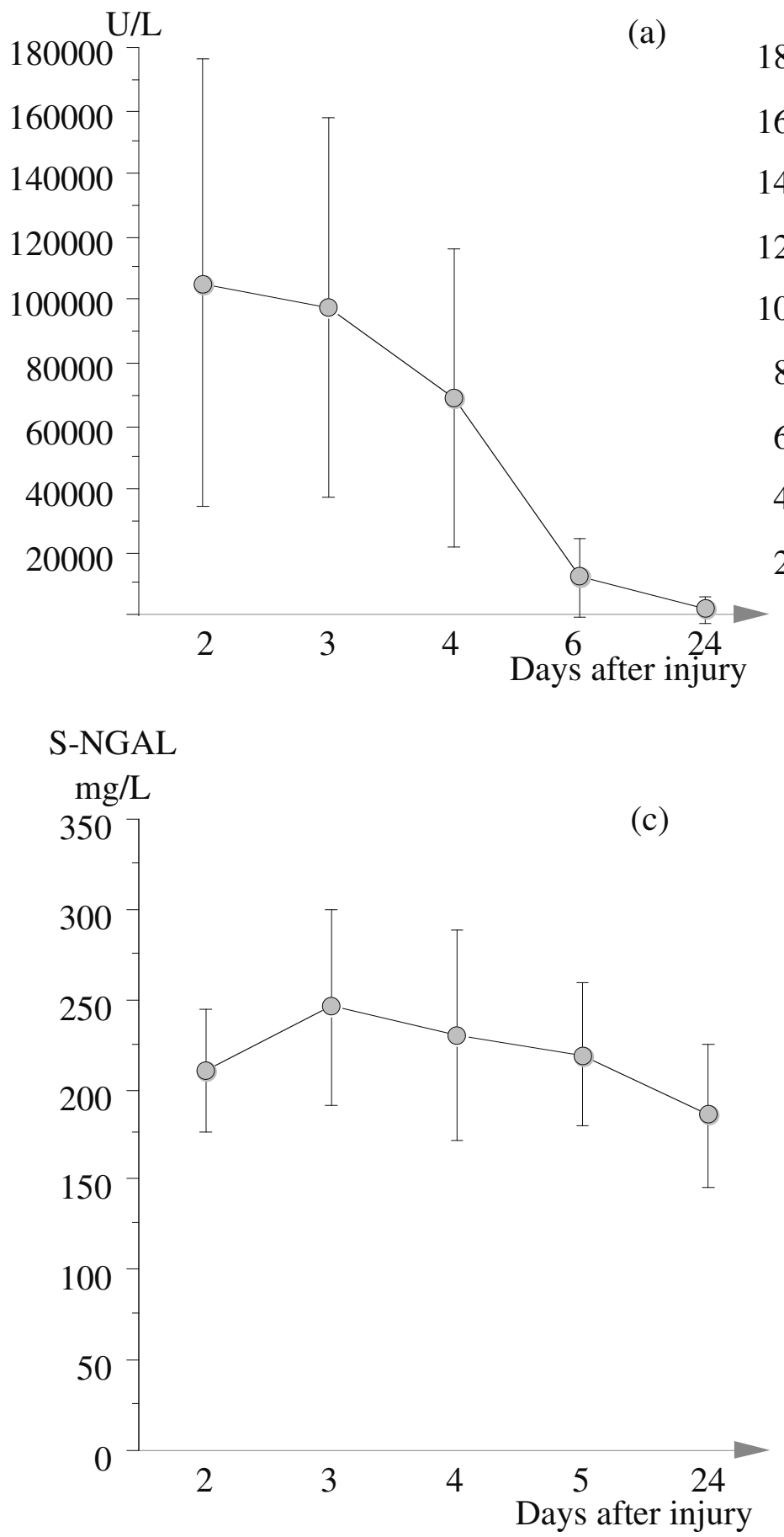

S-Myoglobin

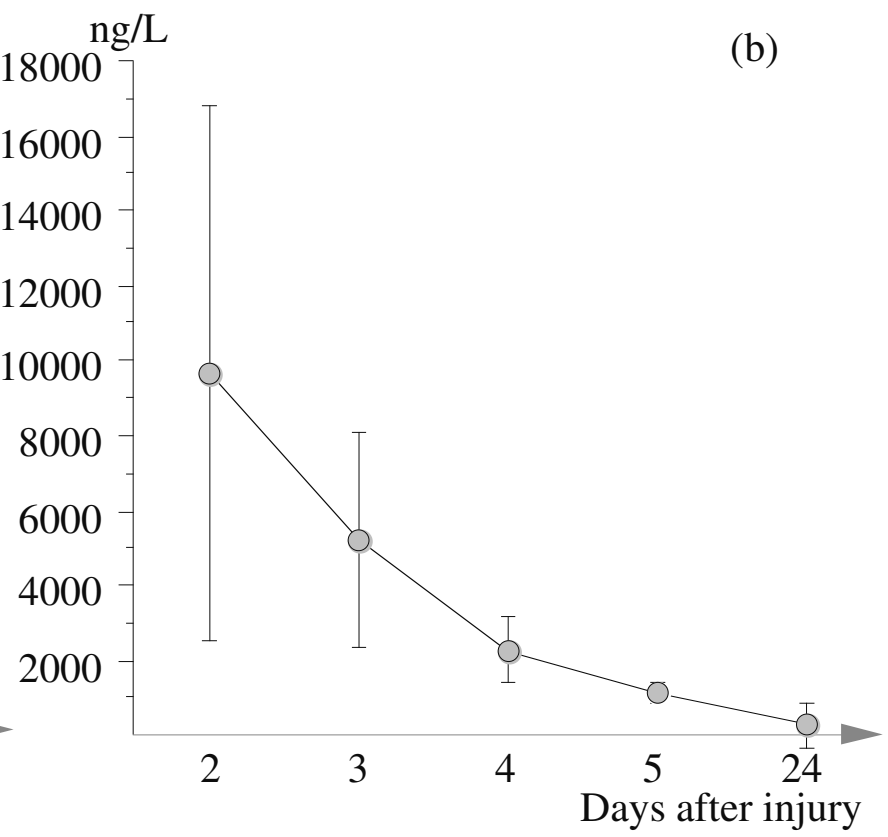

eGFR

$\mathrm{mL} / \mathrm{min}$

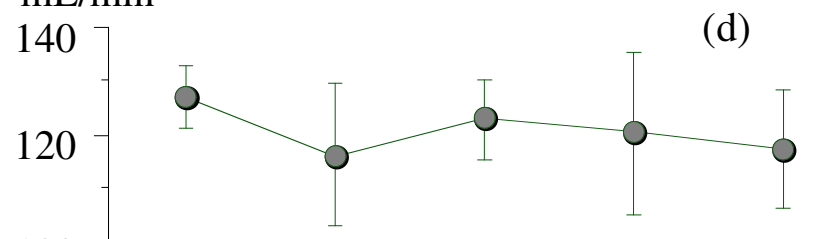

Figure 1 Serial parameters of muscular and renal injury in eight patients. The mean serum concentrations ( \pm SD) of (a) creatine kinase (CK), (b) myoglobin, (c) neutrophil gelatinase-associated lipocalin (NGAL) and (d) estimated glomerular filtration rate (eGFR) during the days following exertional muscular injury. Laboratory reference intervals: CK 50-400 U/L, myoglobin 30$80 \mu \mathrm{g} / \mathrm{L}$ and eGFR $93-131 \mathrm{~mL} / \mathrm{min}$. Day 0, debut of severe muscular symptoms with discoloured urine in the afternoon.

On day 3, the patients had significantly higher serum concentrations of NGAL than the controls. Three weeks later, NGAL concentrations had decreased significantly from peak levels (table 2, figure 1).

\section{DISCUSSION}

The present findings confirm that sustained highintensity physical activity is a crucial risk factor for the development of exertional rhabdomyolysis. All the patients reported that they continued with their highintensity exercise despite significant muscular pain. 
Table 3 Self-reported physical activity during the last 3 days before debut of rhabdomyolysis with discoloured urine

\begin{tabular}{|c|c|c|c|c|c|c|c|c|c|}
\hline & \multicolumn{3}{|c|}{ Day -2 (Sunday) } & \multicolumn{3}{|c|}{ Day -1 (Monday) } & \multicolumn{3}{|c|}{ Day 0 (Tuesday) } \\
\hline & $\begin{array}{l}\text { Exercise } \\
\text { type* } \\
\text { A/S/M/ } \\
\text { No }\end{array}$ & $\begin{array}{l}\text { Exercise } \\
\text { durationt } \\
\text { (min) }\end{array}$ & $\begin{array}{l}\text { Exercise } \\
\text { intensity }\end{array}$ & $\begin{array}{l}\text { Exercise } \\
\text { type* } \\
\text { A/S/M/ } \\
\text { No }\end{array}$ & $\begin{array}{l}\text { Exercise } \\
\text { durationt } \\
\text { (min) }\end{array}$ & $\begin{array}{l}\text { Exercise } \\
\text { intensitył }\end{array}$ & $\begin{array}{l}\text { Exercise } \\
\text { type* } \\
\text { A/S/M/ } \\
\text { No }\end{array}$ & $\begin{array}{l}\text { Exercise } \\
\text { durationt } \\
\text { (min) }\end{array}$ & $\begin{array}{l}\text { Exercise } \\
\text { intensity }\end{array}$ \\
\hline $\begin{array}{l}\text { Patients, } \\
n=8\end{array}$ & $5 / 0 / 1 / 2$ & $19 \pm 16$ & $5.6 \pm 1.7$ & 0/8/0/0 & $137 \pm 55$ & $9.6 \pm 0.5$ & $1 / 7 / 0 / 0$ & $69 \pm 24$ & $7.6 \pm 1.4$ \\
\hline \multirow{2}{*}{$\begin{array}{l}\text { Controls, } \\
n=26\end{array}$} & $5 / 3 / 5 / 13$ & $28 \pm 36$ & $2.0 \pm 2.5$ & 1/16/7/2 & $76 \pm 45$ & $5.1 \pm 3.2$ & $7 / 7 / 9 / 3$ & $59 \pm 40$ & $4.9 \pm 3.2$ \\
\hline & n.s. & n.s. & $p=0.002$ & n.s. & $p=0.004$ & $\mathrm{p}=0.002$ & $p=0.02$ & n.s. & $p=0.04$ \\
\hline
\end{tabular}

Day 0, debut of severe muscular symptoms with discoloured urine in the afternoon.

*Exercise type: four categories; $A$, aerobic training; S, strength training; $M$, mixed training; No, no exercise.

$\dagger$ Exercise duration: self-reported by questionnaire (min, mean \pm SD).

$\ddagger$ Exercise intensity: self-reported by questionnaire (10 levels (1-10) mean \pm SD).

Therefore, failure to identify individual physical performance limits—-both at an individual and supervisory level-appears to play an important role. However, at an early stage, it may be difficult to distinguish between ordinary training soreness and pathological muscle pain of rhabdomyolysis before it is too late. Typically, rhabdomyolysis occurs in healthy people when exposed to unaccustomed exercise, as was the case for these new recruits.

\section{Causes of exertional rhabdomyolysis}

Previous reports have been somewhat conflicting on the relative importance of work intensity, duration and volume. ${ }^{16}$ In the present study, exercise intensity, duration and type were all significant determinants of exertional rhabdomyolysis in univariate models. The patients reported higher intensity at all time-points during the 3-day period prior to hospitalisation for rhabdomyolysis. However, in a multivariate model, exercise intensity on day -1 appeared as the only independent predictor of exertional rhabdomyolysis. At this time-point all of the patients reported an intensity score of 9 or 10 . This may indicate that the risk of rhabdomyolysis is present primarily at the highest exercise intensity levels, whereas lower levels carry less risk of exertional rhabdomyolysis. Moreover, it appears to be possible to quantify the risk of rhabdomyolysis by a simple questionnaire.

Patients and controls had the same aerobic capacity at enrolment for military service, but patients had lower muscular strength. This finding suggests that patients were at a good fitness level, but had less experience with muscular training, and therefore more prone to overuse injury. The present study provides no definite answers, but it is possible that a combination of personal ambition, external pressure and insufficient understanding of the risks paved the way for exertional muscular injury.
The findings need to be interpreted with caution due to small sample size. However, there are few confounding factors: Both patients and controls were previously healthy and had similar background in regard to age, gender, BMI, fitness and ethnicity. We did not test for the asymptomatic sickle cell trait or genetic muscle diseases that may predispose for rhabdomyolysis. ${ }^{17}{ }^{18}$ However, the patients did not report previous episodes of rhabdomyolysis and had muscular strength within normal limits. Therefore, we think that underlying genetic disorders were of no importance in the present study. Furthermore, there was little negative influence from ambient temperature, alcohol, legal or illicit drugs, toxins or metabolic disorders. ${ }^{13}$ Admittedly, recall bias may be possible.

\section{Prevention of exertional rhabdomyolysis}

The present findings suggest some possible targets for the prevention of exertional rhabdomyolysis. However, it is important to emphasise that these measures need to be tested in future prospective studies.

First, prevention of exertional rhabdomyolysis requires increased awareness and education, both directed against individuals who participate in physical exercise and others who supervise physical exercise.

Second, the use of a self-perceived muscular intensity scale may be a useful aid to guide the intensity level of physical exercise.

Third, complementary use of CK concentrations may be of help in case of uncertainty. A mildly elevated CK level in serum is common after physical exercise and may be regarded as a normal response. Mougios ${ }^{19}$ reported an adjusted laboratory reference interval for male athletes during training and competition: 82 $1083 \mathrm{U} / \mathrm{L}$. Serum CK concentrations rising above $5000 \mathrm{U} / \mathrm{L}$ indicate significant muscle injury with risk of acute kidney injury. ${ }^{20}$ In the present study, the patients had peak CK levels 10-50 times higher than this limit. 


\section{Biomarkers of acute kidney injury}

Myoglobin is released from injured muscle and filtered by the kidneys, imparting a dark red-brown colour to the urine. ${ }^{21}$ The iron-containing myoglobin has toxic effects in the kidney, such as vasoconstriction, cast formation and proximal tubular injury. ${ }^{1}$ High levels of serum myoglobin appear to predict acute kidney injury, especially with concentrations over $15000 \mu \mathrm{g} /$ L. ${ }^{22}$

In the present study, the eight patients had high serum myoglobin levels with potential risk of kidney injury, but maintained a stable kidney function. It appears that myoglobinuria seldom causes acute kidney failure in patients without volume depletion. ${ }^{1}$

In clinical practice, kidney function is evaluated by means of serial creatinine levels. However, serum creatinine may be regarded a slow and insensitive biomarker as concentrations do not rise above normal until a significant amount of kidney function has been lost. ${ }^{23}$ Cystatin C may be somewhat better for detecting changes in glomerular filtration rate. ${ }^{24}$ In the present study, all the patients had stable and normal GFR, as estimated by both creatinine and cystatin $\mathrm{C}$.

The new biomarker NGAL appears to be related to tubular injury or stress. ${ }^{25}$ After acute renal injury the tubular cells undergo a complex sequence of events. As a part of this, NGAL is rapidly upregulated and concentrations increase markedly in urine and plasma. ${ }^{26}$ Therefore, NGAL has been advocated as an early and more sensitive marker of acute kidney injury. ${ }^{27} 28$ NGAL concentrations may be influenced by other factors such as pre-existing renal disease and infections. The best results for NGAL as a marker of acute kidney injury have been demonstrated in young populations without comorbidities and with a welldefined timing of the pathogenic event, such as in the present study. ${ }^{27}$ NGAL has diverse functions in the kidney; it may modulate cellular responses, have ironbinding properties and may serve to limit tubular damage. ${ }^{29}$ We observed elevated serum levels of NGAL in our patients, and this probably indicates stress and/ or structural damage of the tubular cells. Three weeks after the injury, NGAL concentrations had decreased from peak levels and there was no evidence of permanent kidney injury.

In conclusion, sustained high-intensity physical activity, exceeding muscular functional capacity, is a crucial risk factor for exertional rhabdomyolysis. During physical exercise it may be difficult to distinguish between ordinary muscular training soreness and alarming muscular pain at the initial stages. However, the present findings indicate that it may be possible to quantify the risk of rhabdomyolysis by a simple questionnaire.

Although traditional markers of renal function often remain within normal limits in exertional rhabdomyolysis with gross pigmenturia, elevated serum NGAL may indicate the presence of renal stress or subclinical injury.

In the future, measures should be taken to prevent exertional rhabdomyolysis by providing information and awareness of the condition to persons who participate in or supervise physical exercise.

\section{Limitations}

A rhabdomyolysis questionnaire will need to be validated in a larger prospective study with calculation of sensitivity and specificity and receiver operator characteristic analysis. Furthermore, specific questions should be added to exclude underlying genetic diseases.

Acknowledgements The authors want to thank the staff at the local military health service for their invaluable help. We thank the recruits for their interest and efforts. We are grateful for the support from The Joint Medical Service of The Norwegian Armed Forces.

Contributors TA and S $\emptyset$ designed the study. TA, TD, TOD, EMS and IST recruited subjects and obtained clinical data. TA, TD, TOD and Å obtained and/or analysed blood samples. TA and $S \varnothing$ analysed data and drafted the manuscript. All authors actively contributed in reviewing, revising and approving the manuscript.

Funding Free research funding from the Research Group of Internal Medicine, Stavanger University Hospital.

Competing interests Two of the authors were employed by the Norwegian Armed Forces at the time. For the remaining authors, no conflicts of interest were declared.

\section{Patient consent Obtained.}

Ethics approval Provided by The Regional Ethics Committee, REK west, University of Bergen, Bergen, Norway (2015/1509/REK vest).

Provenance and peer review The study was conducted without any interference from the Norwegian Armed Forces and is not commissioned; externally peer reviewed. The Joint Medical Service played no role in design of the study, interpretation of data or preparation of the manuscript.

Data sharing statement All study data available from the authors. There are no additional unpublished data.

Open Access This is an Open Access article distributed in accordance with the Creative Commons Attribution Non Commercial (CC BY-NC 4.0) license, which permits others to distribute, remix, adapt, build upon this work noncommercially, and license their derivative works on different terms, provided the original work is properly cited and the use is non-commercial. See: http:// creativecommons.org/licenses/by-nc/4.0/

(C) Article author(s) (or their employer(s) unless otherwise stated in the text of the article) 2017. All rights reserved. No commercial use is permitted unless otherwise expressly granted.

\section{REFERENCES}

1 Zager RA. Rhabdomyolysis and myohemoglobinuric acute renal failure. Kidney Int 1996;49:314-26.

2 Huerta-Alardín AL, Varon J, Marik PE. Bench-to-bedside review: Rhabdomyolysis - an overview for clinicians. Crit Care 2005;9:158-69.

3 Sinert R, Kohl L, Rainone T, et al. Exercise-induced rhabdomyolysis. Ann Emerg Med 1994;23:1301-6.

4 Giannoglou GD, Chatzizisis YS, Misirli G. The syndrome of rhabdomyolysis: Pathophysiology and diagnosis. Eur J Intern Med 2007;18:90-100.

5 Wrogemann K, Pena SD. Mitochondrial calcium overload: a general mechanism for cell-necrosis in muscle diseases. Lancet 1976;1:672-4.

6 Lee G. Exercise-induced rhabdomyolysis. R I Med J 2014;97:22-4. 
7 Smoot MK, Amendola A, Cramer E, et al. A cluster of exertional rhabdomyolysis affecting a Division I Football team. Clin J Sport Med 2013;23:365-72.

8 USAF. Update: Exertional rhabdomyolysis, active component, U.S. Armed Forces, 2010-2014. MSMR 2015:22:22-5.

9 Armed Forces Health Surveillance Branch. Update: Exertional rhabdomyolysis, active component, U.S. Army, Navy, Air Force, and Marine Corps, 2011-2015. MSMR 2016;23:21-4.

10 Lin $\mathrm{H}$, Chie W, Lien $\mathrm{H}$, et al. Epidemiological analysis of factors influencing an episode of exertional rhabdomyolysis in high school students. Am J Sports Med 2006;34:481-6.

11 Galvez R, Stacy J, Howley A, et al. Exertional rhabdomyolysis in seven division-1 swimming athletes. Clin J Sport Med 2008;18:366-8.

12 Alpers JP, Jones LK. Natural history of exertional rhabdomyolysis: a population-based analysis. Muscle Nerve 2010;42:487-91.

13 Bagley WH, Yang H, Shah KH, et al. Intern Emerg Med 2007;2:210-8.

14 Aandstad A, Hageberg R. Reliability and validity of a New Treadmill Test for Screening prospective military recruits. Medicine \& Science in Sports \& Exercise 2012;44(Suppl 2):204-5.

15 Levey AS, Stevens LA, Schmid CH, et al. A new equation to estimate glomerular filtration rate. Ann Intern Med 2009;150:604-12.

16 Baird MF, Graham SM, Baker JS, et al. Creatine-kinase- and exercise-related muscle damage implications for muscle performance and recovery. J Nutr Metab 2012;2012:1-13.

17 Scalco RS, Snoeck M, Quinlivan R, et al. Exertional rhabdomyolysis: physiological response or manifestation of an underlying myopathy? BMJ Open Sport Exerc Med 2016;2:e000151.

18 Nelson DA, Deuster PA, Carter R, et al. Sickle Cell Trait, Rhabdomyolysis, and Mortality among U.S. Army Soldiers. N Engl J Med 2016;375:435-42.
19 Mougios V. Reference intervals for serum creatine kinase in athletes. Br J Sports Med 2007;41:674-8.

20 Brown CV, Rhee P, Chan L, et al. Preventing renal failure in patients with rhabdomyolysis: do bicarbonate and mannitol make a difference? J Trauma 2004;56:1191-6.

21 David WS. Myoglobinuria. Neurol Clin 2000;18:215-43.

22 Premru V, Kovač J, Ponikvar R, et al. Use of myoglobin as a marker and predictor in myoglobinuric acute kidney injury. Ther Apher Dial 2013;17:391-5.

23 Bellomo R, Kellum JA, Ronco C. Defining acute renal failure: physiological principles. Intensive Care Med 2004;30:33-7.

24 Ahlström A, Tallgren M, Peltonen S, et al. Evolution and predictive power of serum cystatin $\mathrm{C}$ in acute renal failure. Clin Nephrol 2004;62:344-50.

25 Devarajan P. Review: neutrophil gelatinase-associated lipocalin: a troponin-like biomarker for human acute kidney injury. Nephrology 2010;15:419-28.

26 Mishra J, Mori K, Ma Q, et al. Amelioration of ischemic acute renal injury by neutrophil gelatinase-associated lipocalin. J Am Soc Nephrol 2004;15:3073-82.

27 Vanmassenhove J, Vanholder R, Nagler E, et al. Urinary and serum biomarkers for the diagnosis of acute kidney injury: an in-depth review of the literature. Nephrol Dial Transplant 2013;28:254-73.

28 Lippi G, Sanchis-Gomar F, Salvagno GL, et al. Variation of serum and urinary neutrophil gelatinase associated lipocalin (NGAL) after strenuous physical exercise. Clin Chem Lab Med 2012;50:1585-9.

29 Schmidt-Ott KM, Mori K, Li JY, et al. Dual action of neutrophil gelatinase-associated lipocalin. J Am Soc Nephrol 2007;18:407-13. 